\title{
Una nueva mirada a la formación docente como camino hacia equidad de género
}

\section{A New Look at Teaching Education as a Way for Gender Equality}

\author{
Ana María Hernández Segura ${ }^{l}$ \\ División de Educación Básica Centro de Investigación y Docencia en Educación \\ Universidad Nacional \\ Heredia, Costa Rica \\ ahernans@una.ac.cr
}

Recibido 01 de noviembre de 2010 • Aceptado 09 de marzo de 2011

\begin{abstract}
Resumen.El objetivo de este artículo es llevar a la reflexión sobre el tema de las relaciones asimétricas entre los hombres y las mujeres, las cuales representan una desventaja en especial para las mujeres. Lo anterior representa una realidad histórica que se vive en todos los contextos sociales, y la institución educativa no escapa a esta situación. Las relaciones de desigualdad e inequidad han venido a permear los roles asignados socialmente en razón de la identidad sexual, y en los cuales las mujeres se ven discriminadas en la igualdad de oportunidades para su pleno desarrollo como ser humano.Resulta importante reconocer las luchas que se han venido dando para acabar con esta desigualad y discriminación; pero todavía quedan muchas tareas pendientes. Es justamente la educación un camino que puede conducir a la senda donde hombres y mujeres gocen de los mismos derechos y deberes, no sólo en el papel, sino que esas políticas se concreten en la vida cotidiana. De ahí que la formación de las futuras educadoras y educadores, requiere de una nueva mirada en el diseño e implementación de los planes de estudios, los cuales incorporen, de manera explícita y profunda, la categoría analítica de género, para promover, desde el preescolar hasta el nivel universitario, cambios en las prácticas sexistas.
\end{abstract}

Palabras claves. Formación docente, currículo, prácticas sexistas.

Abstract. The purpose of this paper is to reflect upon the asymmetric relationships between men and women -relationships that have represented a disadvantage particularly for women-. This has been a historical reality in all social contexts, and education institutions are not the exception. The inequality and inequity relationships have permeated the socially designated roles, in terms of sexual identity, which has contributed to women's discrimination in accessing equal opportunities for their full development as human beings.

It is important to acknowledge the fights against inequality and discrimination; however, many tasks are still pending. Education is, precisely, one way to such a path in which men and women will enjoy the same rights and duties, not only on paper, but also in the everyday life. That is why the formation of future teachers requires a new vision in terms of the design and implementation of study plans explicitly including the analytical category of gender to promote changes in sexist practices, from preschool to the university level.

Keywords. Teaching formation, curriculum, sexist practices.

\footnotetext{
Educadora, Máster en Educación con mención en Docencia Universitaria, Universidad Nacional, Costa Rica. Estudiante del Doctorado Latinoamericano de la Universidad Estatal a Distancia, Costa Rica. Profesora de la Carrera de Educación Preescolar, División de Educación Básica del Centro de Investigación y Docencia en Educación, de la Universidad Nacional, Costa Rica.
} 
"Lograr la conversión de las mujeres en sujetos precisamente en el ámbito en que han sido cosificadas"

(Lagarde, 1997)

\section{Punto de partida}

La realidad actual evidencia la influencia histórica de la sociedad patriarcal, donde ha prevalecido una desigualdad de oportunidades y derechos en prejuicio de las mujeres. De acuerdo con Lagarde (s. f.), producto de esa sociedad patriarcal, alrededor de la mujer se ha tejido una serie de calificativos como: opresión, objeto, cautiverio, enajenación, pobreza, dominación, explotación laboral, sumisión; mientras que para el hombre sobresalen: sujeto, dominio, poder, acción. Es decir, mujer inmanente y hombre trascendente, en palabras de De Beauvoir (2000).

Lo anterior implica que desde esa visión androcentrista y hegemónica, las relaciones entre hombre y mujer han estado basadas en la opresión y desigualdad, lo cual también ha tenido sus repercusiones en el desarrollo humano social y económico; así lo menciona Lagarde (s. f.) cuando cita los resultados de un estudio de índice de desarrollo humano, el cual plantea que: "a mayor opresión de género, mayor atraso, mayor pobreza y peores condiciones de vida caracterizan a la mayoría de los países" (p. 3). De ahí que, al igual que la autora citada, coincido en la urgencia de esa nueva mirada al mundo de las relaciones entre hombres y mujeres, dentro de un marco de derechos y justicia social. Lagarde (s. f.) nos invita a ese cambio: "Confía en que si se modifica la asimetría política de mujeres y hombres, será posible acceder a formas sociales que permitan satisfacer adecuadamente las necesidades vitales, así como mejorar la calidad de vida personal y comunitaria" (pp. 3-4). Creo que ese es uno de los objetivos primordiales en esta lucha; la calidad de vida para tod as y todos.

Esas ideas androcentristas y patriarcales que se han vivido históricamente, son las que han venido a impregnar las prácticas educativas sexistas en la educación, tal como lo señalan Subirats (1999) y Graña (2008), cuando mencionan el clásico de Emilio-Sofía, propuesto por Rosseau, con roles asignados por la condición de sexo o el tipo de educación sexista-masculina, impartida desde el Siglo de las Luces.

Esa posición, vigente hoy día, es producto de la creencia determinista basada en la naturaleza, o en la "voluntad divina", como lo manifiesta Lagarde (s. f.): "Así se cree en la ley natural, y en las naturalezas humana, femenina y masculina-como entelequias eternas y ahistóricas" (p. 16), lo cual hace que prevalezcan condiciones de control y poder sobre las mujeres, que no se cuestione este tipo de relaciones y se acepten como parte de un proceso natural y determinista. Scott (1996) también hace alusión a elementos normativos que tienden a establecer como naturales esas relaciones desiguales de género, y destaca las doctrinas religiosas, educativas, científicas y legales. Para Lamas (1996b), esos papeles sexuales, considerados como naturales e inmutables, no son tal, para ella son constructos sociales y, por tanto, sí se pueden modificar, aunque reconoce que esos códigos culturales heredados, que se evidencian en la explotación e injusticia, son difíciles de transformar.

Por todo lo anterior, es importante llamar a la reflexión de lo que se entiende por sistema patriarcal y sus repercusiones directas en las relaciones asimétricas entre hombres y mujeres. En este sentido, la definición planteada por Lagarde (s. f.) resulta de gran utilidad para dimensionar la situación histórica de dichas relaciones: "El sistema patriarcal es un sistema de propiedad social y privada de las mujeres a través de la apropiación, posesión, usufructo y deshecho, de sus cuerpos vividos, de su subjetividad, de sus obras. Las normas regulan el control sobre su sexualidad, sus 
capacidades reproductivas, su erotismo, su maternidad, su capacidad amatoria, incluso sobre su salud" (p. 19). Es decir, dentro de ese marco, las mujeres no son seres humanos autónomos ni libres: todo lo contrario, están presas en la cárcel del control y enajenación de una concepción patriarcal, muy arraigada por ese "habitus" de la dominación masculina, como lo llama Bourdieu (2000). Y uno de los contextos donde se hacen visibles las influencias de la anterior definición es, precisamente, en el contexto educativo.

\section{Traspasando las fronteras del género: el reto de eliminar los contenidos sexistas de la educación}

El sexismo es una forma de discriminación que utiliza al sexo como criterio de atribución de capacidades, valoraciones y significados creados en la vida social (...) en el sexismo la diferencia se coloca en una escala jerárquica que sostiene el argumento de que las mujeres son inferiores (...). (Secretaria de Estado de Educación de República Dominicana, 2008, p. 9)

No se puede negar, como lo señala Chaves (2006): "La transmisión del capital cultural acumulado de generación en generación, se encarga de interiorizar la cultura dominante en los sectores subalternos, lo que contribuye a perpetuar y legitimar la hegemonía económica-social, cultural de los que tienen el poder (...)" (p. 188), situación que repercute en la vida cotidiana y que se viene a posicionar todavía más como producto de la influencia de diversas instituciones como la religión, los medios de comunicación y, en especial, la educación. Por esto, romper con estás prácticas hegemónicas constituye todo un reto y desafío.

Tampoco se pueden obviar los esfuerzos que diversos grupos sociales organizados han venido realizando para que la carga de contenidos sexistas en el campo educativo se vaya extinguiendo. En este caminar hacia esta importante meta, se han dado avances y retrocesos, es decir, una lucha constante que inició con más fuerza desde los años 70 con los movimientos feministas.

En este devenir de los ideales por el acceso a la igualdad de los derechos humanos para todos y todas, es innegable el aporte de disciplinas como la Sociología, Antropología, Psicología, las cuales han venido a dar otra mirada al tema de las relaciones asimétricas entre hombres y mujeres, y a superar la visión reduccionista y discriminatoria desde la óptica biológica (Subirats, 1994).

El tema de los contenidos sexistas en la educación está presente de forma explícita, plasmado en el currículo oficial, pero también por medio del currículo oculto y, a mi juicio, puede ser más perjudicial para enfatizar esas diferencias por sexo que discriminan y afectan con fuerza a las mujeres.

El sistema educativo en su conjunto tiene gran impacto y poder sobre los individuos, porque la escuela es un espacio que moldea, socializa, pone reglas y pautas a los comportamientos de sus integrantes. Aquí cabe el concepto de "microfísica del poder", de Foucault (citado por Subirtats, 1999), a lo que agregó:

La escuela, el aula, la interacción cotidiana, permitieron descubrir que el sistema educativo es mucho más que un expendedor de títulos, es un espacio de socialización diferenciada, en las que hay reglas sumamente estrictas, aunque invisibles que moldean con gran precisión las personalidades individuales, que construyen el éxito y el fracaso, que separan a quienes están destinados a tener responsabilidades y a tomar decisiones de quienes están destinados a plegarse a ellas. (Subirats, 1999, pp. 21-22) 
Es importante aclarar que esa influencia patriarcal no sólo es evidente en los niveles primarios y secundarios de la educación, también se evidencian en el plano de la educación superior. Como lo menciona Acker (1995), en la "universidad" patriarcal hay ruptura, brechas y contradicciones y, en este ámbito, las luchas también son serias y necesarias.

Por su parte, Araya (2004) hace referencia a que pese a los esfuerzos que se han venido dando para eliminar elementos discriminatorios hacia las mujeres, prevalecen condiciones societarias, y entre ellas destacan las relaciones de poder y dominio, las referentes a la división sexual del trabajo, el machismo (posesión y agresión hacia la mujer), embarazos en adolescentes, las relaciones amatorias, entre otras.

Esas condiciones societarias estereotipadas son señaladas también por Bourdieu (2000), por ejemplo, lo relacionado con la virilidad y la violencia. Desde esta óptica, el hombre es conceptualizado con capacidad reproductora, sexual y social; con aptitud para el combate y el ejercicio, deportes de competición y violencia; rituales escolares o militares (violaciones colectivas, visitas a burdeles para afirmar su virilidad). Mientras que a las mujeres se les visualiza desde la virginidad, fidelidad, debilidad y expuestas a la ofensa y a los miedos que suscita lo femenino.

Estos ejemplos evidencian que el camino por recorrer en las luchas por este ideal de igualdad en las relaciones es todavía largo y requiere de un proceso constante para que las mujeres nos empoderemos y dejemos de ser ese grupo de los “oprimidos”, como lo llama Freire.

Por tanto, las instituciones educativas siguen actuando, aunque no siempre de forma intencionada, como un lugar de reproducción de los sistemas de género" (prologo a Acker, 1995, p. 11).

La influencia de los contenidos sexistas en la educación, así como en la construcción de la identidad y subjetividad, se ve afectada directamente por los medios de comunicación, como lo enfatiza Chaves (2006):

En este proceso, intervienen (...) las relaciones sociales que rodean a las personas en la familia y en la escuela, como también los diferentes medios de comunicación que trasmiten informaciones, valores, concepciones ideológicas que cumplen una función más dirigida a la reproducción de la cultura dominante que a la reelaboración crítica y reflexiva de la misma (...). (p. 189)

Esta influencia es tratada por Belmonte y Guillamón (2008), quienes insisten en la importancia de educar a los televidentes, ya que por este medio también se construyen identidades: "La televisión, como aparato social, es un poderoso medio de producción del sentido, y en numerosas ocasiones contribuye a normalizar y naturalizar aquello que no es sino fruto de la compleja construcción social (...)” (p. 116).

De ahí que tenemos por delante una ardua tarea para traspasar las fronteras de género en la dinámica educativa y también en la vida cotidiana; debemos pensar en alternativas que, en el corto y mediano plazo, lleven a la consolidación del reto de eliminar las prácticas sexistas. Entre ellas están el diseño de un currículo que supere esa visión reduccionista, así como cambios urgentes en el tema de la formación docente.

Es preciso insistir por una educación no sexista, donde las mujeres ocupen puestos de decisión, que por lo general han estado en manos de hombres, porque históricamente la mujer ha sido tan discriminada en este espacio como en tantos otros.

\section{Reflexiones en torno al currículo}

Es importante tener presente que el currículo, al igual que la escuela y el lenguaje, no son elementos neutrales; están cargados política e ideológicamente y, por tanto, son poderosas 
herramientas para mantener el orden social establecido y la reproducción de las desigualdades y, en este caso particular, las desigualdades en las relaciones hombre-mujer.

En lo referente a las implicaciones del currículo oculto, Araya (2004) menciona que este tiene que ver con todas las interacciones cotidianas que se dan en el aula, es decir, de manera implícita trasmite conocimientos, destrezas, valores, actitudes, porque las expectativas de los docentes se reflejan en esas interacciones, que llegan a clasificar y discriminar por género; además plantea cómo, de manera solapada, las imágenes de los libros de texto también son parte de ese currículo oculto, "(...) en ellos vehiculizan valores no explicitados que conllevan pautas y tradiciones sexistas (papeles asignados a hombres y mujeres, participación política y comunal diferenciada (...)" (Araya, 2004, p. 7).

Debemos ser concientes del poder que ejerce el currículo oculto en las relaciones áulicas, porque como lo mencionan Fioretti, Tejero y Díaz (2002), tanto los contenidos curriculares, como los comportamientos y las relaciones docente-alumno, producen "conductas modélicas". Esas conductas son las que más calan o permean en la formación de los estudiantes; por tanto, debemos ser coherentes en nuestras acciones cotidianas y con los discursos que decimos manejar.

Uno de los instrumentos que pueden permitir dar pasos en el cambio de las prácticas sexistas es el currículo. Este debe partir de una definición como construcción social y cultural, como una forma de organización de las prácticas educativas humanas. Grundy (1998) indica: "Esto significa que hemos de buscar el currículum, no en la estantería del profesor, sino en las acciones de las personas inmersas en la educación (...) pensar en el currículum es pensar en cómo actúa e interactúa un grupo de personas en ciertas situaciones" (p. 21).

Es decir, podemos actuar sobre él, contribuir a su construcción de cara al concepto de hombre y mujer, de sociedad y mundo que queremos en estos tiempos de lucha por la igualdad formal y real de los derechos humanos, en especial para todos aquellos grupos históricamente marginados. Queremos que la escuela o institución educativa deje de ser ese espacio de reproducción ideológica, de relaciones de poder que se dan en la sociedad y que se reproducen en el microcosmos del aula.

Gimeno (2002) se refiere al tema del currículo como un concepto esencial que permite la comprensión de la práctica educativa y de su función socializadora; además, es el instrumento mediante el cual se concretan los fines sociales y culturales, es decir, plasma un determinado modelo educativo, pero no como objeto estático, sino es una praxis y una expresión de la práctica pedagógica.

Desde esta definición, se puede diseñar un currículo que, de manera explicita, contemple la temática de género, a lo largo de todo el proceso formativo, y que no sea, como lo anota la investigación Ketterer (2008), una escasa incorporación en la planificación educativa.

\section{Pensar diferente: La formación docente como alternativa para la ruptura de prácticas sexistas en la educación}

Como se ha mencionado, hacer esas rupturas en las prácticas sexistas implica todo un reto y un cambio de mentalidad que lleve a concretar este ideal de igualad de oportunidades en el disfrute pleno de los derechos humanos.

En este sentido, Foucault (1984, citado por Aguado, 2003) nos invita a pensar diferente y señala que: "Hay momentos en la vida en los que la cuestión de saber si uno puede pensar de forma distinta de la que piensa y percibir de una manera distinta a como uno observa, es indispensable para continuar mirando o reflexionando" (p. vi), es decir, debemos perder el temor de iniciar luchas que permitan la ruptura de viejas prácticas segregadoras. 
Esta autora plantea el tema de la educación multicultural como una respuesta para atender la diversidad, y dentro de la cual se acepta la complejidad del ser humano y la convivencia de diversos grupos e implica: interacción, intercambio, romper el aislamiento, reciprocidad, solidaridad entre culturas, reconocer y aceptar los valores de otros, lo cual exige modificar contenidos y estrategias curriculares, para superar la visión asimilacionista. Insiste en que el sistema educativo es una herramienta clave para favorecer la igualdad de oportunidades y para construir una ciudadanía democrática. En esto coincide con S. Araya (Comunicación personal, 12 de junio de 2010), quien señala que la educación es un proceso clave para construir una visión crítica y una construcción de ciudadanía libre, sin jerarquías por condición de sexo, donde tanto hombres y mujeres sean Sujetos con igualdad de condiciones de acceso a los derechos.

Darling-Hammond (1996, citado por Aguado, 2003) agrega que para logar un cambio y una real igualdad de oportunidades traducida en igualdad de opciones escolares de calidad para todos, son imprescindibles cambios estructurales y permanentes en recursos financieros, prácticas escolares y formación del profesorado, es decir, se requiere una adecuada formación del profesorado, para lograr tener un discurso coherente con la práctica del aula.

Esta formación docente debe contemplar varios aspectos y conceptos, por ejemplo, Stainback y Stainback (1999) aluden al tema de las aulas inclusivas, aquellas donde se "celebre" diversidad, y se formen comunidades. Plantean un currículo que ensalza las diferencias y construye sobre ellas: "Crear una escuela inclusiva en la que se reconozca, valore y respete a todos los alumnos supone prestar atención a lo que se enseña y al modo de enseñarlo" (p. 37).

Estos autores enfatizan que no sólo hay que diseñar estrategias docentes y determinar el currículo que responda al conjunto de diferencias de los alumnos, sino que el currículo debe afrontar las diversas formas en que difieren los estudiantes, ya que el no prestar atención directa a eso y no reconocer las muchas formas en que difieren las personas, trasmite el mensaje de que no se puede ni se debe hablar sobre ese tema. En este caso, las diferencias de género. Plantea, entre otras cosas, "liberar la idea restrictiva y estereotipada sobre lo que pueden hacer las niñas y lo que pueden hacer los niños, abriendo más opciones para su crecimiento y desarrollo" (p. 44). Añade que él docente o la docente estén atentos al lenguaje que emplean, los comportamientos que demuestran, materiales y actividades que facilitan, inclusive a advertencias como "los chicos no lloran" o de sacarlos del área de juegos del hogar y llevarlos a la de bloques y construcción.

El tema de la formación docente es medular, ya que, de acuerdo con Araya (2001), el docente ejerce poder, es una fuerza social que puede actuar a favor del cambio o de la continuidad social. Esta autora plantea el tema de la formación docente desde una óptica reflexiva e innovadora, de manera que se piense en su significado, y como tal es un proceso individual para ir perfeccionando las capacidades de sentir, actuar, imaginar, comprender y aprender, como lo plantea Ferry (1990, citado por Araya, 2001).

Se requiere, con urgencia, la formación de un nuevo docente, que potencie en ellos y ellas la reflexión crítica sobre su práctica, porque el contexto que hoy enfrenta, está más allá de la labor en las cuatro paredes de un aula y más allá que la tradicional tarea de enseñar. El docente de hoy debe ser protagonista en la toma de decisiones de las prácticas educativas y no un simple "hacedor" de lo que otros le dictan desde un escritorio; por tanto, necesita enriquecer su saber y hacer pedagógico, reorganizar y reconstruir su propia experiencia a la luz de los retos y desafíos de este mundo complejo. Pero para esto, como lo señala Gimeno (2002), es precisa una formación de un docente con autonomía, con visión emancipadora, que pueda tomar decisiones y ser responsable de todos los componentes que conforman el currículo que implementa o, como lo anota este autor, un docente con concepciones epistemológicas, para una adecuada selección y concreción de ese currículo crítico y transformador. 


\section{La formación docente para la educación inicial}

La labor docente es de suma importancia para el desarrollo integral de cada una de las personas. Desde sus inicios, fue ejercida y liderada por hombres, pero con el pasar del tiempo, las mujeres se fueron incorporando a este campo, tanto para su propia formación como para trabajar directamente como maestras.

Los hombres, que en un inicio ejercieron estas labores, las fueron abandonando por otras "más productivas", "rentables" o "acordes" a su "status varonil", todo lo cual tiene sus repercusiones en la época actual, pues sigue prevaleciendo un dominio de las mujeres en la labor docente, y con especial énfasis en el área de la educación preescolar. Indica Fernández (2001) que hoy no sólo se discute sobre las desigualdades de clase, sino que "(...) poco a poco se fue abriendo paso la preocupación por otro tipo de desigualdades, concretamente de género" (p. 79). Agrega que esto se dio básicamente por la "feminización galopante" del profesorado.

En este sentido, Berger y Luckmann (1984) indican que "el universo simbólico ordena y por ende legitima los 'roles' cotidianos, las prioridades y los procedimientos operativos, colocándolos, sub specie universi, vale decir, en el contexto del marco de referencia más general que pueda concebirse" (p. 129). Lo que implica que las construcciones culturales de determinados contextos marcan el tipo de papel que deben jugar sus integrantes; por ejemplo, las mujeres siempre están excluidas del poder público y relegado al ámbito doméstico. Y producto de ese orden del universo simbólico también se les asigna, casi de manera exclusiva, su lugar como docentes de preescolar, ya que socialmente se ha construido una imagen de mujer con una serie de características en su personalidad "idóneas" para el ejercicio de la docencia, tales como: sus habilidades innatas de madre, no requieren de altos salarios, más obedientes, capacidad para enseñar, entre otros estereotipos más.

Por los argumentos antes expuestos, cobra relevancia la formación docente de este grupo profesional. En primera instancia, para romper con esos criterios tradicionales de sus características "idóneas", también para empoderarlas con nuevas herramientas que acaben con su condición de subordinación en la sociedad y, finalmente, porque a su vez, tienen la responsabilidad de la formación y educación de niños y niñas en etapas cruciales de su desarrollo. Esto último resulta clave para iniciar, desde esas edades, otra visión en las relaciones equitativas entre hombres y mujeres, dejando de lado la implementación de un currículo sexista. Para esto se requiere promover una formación docente, sin prejuicios, abierta a cambiar de actitud y a modificar el currículo para eliminar los sesgos sexistas. En especial, porque como lo señala Araya (2004), en los niveles de preescolar y de primaria, la gran mayoría de docentes son mujeres.

Aprovechar la etapa de la educación infantil para una construcción identitaria libre de prejuicios y estereotipos condicionados por el "cuerpo", donde se deje de lado el énfasis de supremacía hacia los roles masculinos, resulta de gran importancia. Lagarde (1997) señala: "Como la identidad se conforma por los significados culturales aprendidos y por las creaciones que el sujeto realiza sobre su experiencia a partir de ellas, la complejidad cultural impacta la complejidad de la identidad" (p. 14). Añade que otros elementos como características del cuerpo, religión, clase, género, salud, entre otras, pueden ser elementos que configuren la identidad.

Entonces, la influencia de la sociedad define el concepto o la identidad de hombre o de mujer, es decir, es una construcción dada socialmente y no algo natural, o como lo indica Lagarde, vivimos en un mundo de clasificaciones y una de las que más destacan es ser hombre o mujer.

Justamente en el campo educativo, desde niveles preescolares hasta superiores, se pueden y deben dar las luchas para la equidad de oportunidades y acceso a todo el quehacer de una 
sociedad, sin importar el sexo al cual se pertenece; y favorecer, de esta forma, la autoidentidad o autoconciencia de cada persona, como ser individual, seamos hombres o mujeres. De esta manera, se evitarían situaciones de exclusión e intolerancia por la identidad o características particulares de cada persona. No debemos olvidar que la vida cotidiana se construye con el aporte de cada uno de los miembros de la sociedad.

Otro aspecto a tomar en cuenta sobre la importancia de la formación de docentes para trabajar en el nivel infantil, es lo anotado por Berger y Luckmann (1984). Estos autores hacen referencia al tema de la socialización primaria: "el individuo no nace miembro de una sociedad: nace con una predisposición hacia la socializad y luego llega a ser miembro de la sociedad" (p. 164). Es en este período donde el niño acepta roles y actitudes de los otros significantes, lo internaliza y apropia de ellos, o sea, construye su identidad. Es decir, la socialización primaria es básica para el ser humano. Por otra parte, se refieren a la socialización secundaria, que es cualquier proceso posterior que induce al individuo ya socializado a nuevos sectores del mundo objetivo de su sociedad; por ejemplo, la educación es un tipo de de socialización secundaria. Para Berger y Luckmann (1984), la sociedad es un producto humano y el ser humano, un producto social.

De ahí que la formación docente debe contemplar estos aspectos, porque los primeros años de vida del ser humano son esenciales en su socialización y conformación de la identidad. En este sentido, los centros de educación infantil pueden ser espacios importantes para implementar cambios en las relaciones entre hombres y mujeres, con otra visión y perspectiva, que rompa con viejos paradigmas. Esto es posible con una práctica docente que promueva otro tipo de interacciones, de materiales didácticos y literarios y, en especial, con cambios en el uso de los lenguajes. Porque como lo señalan Berger y Luckmann (1984): "El lenguaje proporciona la superposición fundamental de lógica al mundo social objetivado. Sobre el lenguaje se construye el edificio de la legimitación, utilizándolo como instrumento principal" (p. 87).

Dentro de este marco, es preciso reflexionar sobre muchas de las prácticas vigentes (pero no pertinentes) en los salones de clase de los jardines infantiles. Por ejemplo, Chaves (2002) hace alusión a prácticas conductistas, tales como los ejercicios de apresto basados en el conductismo y que no provocan en los niños la formación de personalidades ni críticas ni reflexivas.

Entre los hallazgos de la investigación que realizo, se evidencia que el desarrollo de la práctica pedagógica observada dista mucho de un currículo emancipador, “(...) tal vez por una estructura institucional que no favorece la práctica pedagógica liberadora o porque no es fácil cambiar visones de mundo, valores y creencias con las que nos hemos construido como personas desde que nacimos y que se reflejan en nuestro modo de actuar" (Chaves, 2002, p. 13). Además, palpé la utilización de lenguaje sexista por parte de la docente, lo que invisibiliza a las mujeres y, como cultura dominante, moldea comportamientos, actitudes y pensamiento. Esto se evidenció en la áreas de juegos, donde se reproducen conductas sexistas estereotipadas, asignadas socialmente por condición de género.

Sobre este tipo de prácticas, Ferro y Carvajal (en prensa), señalan que "El juego es una de las actividades socializadoras más importantes, aprendemos límites, nos comunicamos, tocamos, sentimos, interactuamos con otros niños y niñas, pero el juego, a su vez sirve para que desde temprana edad sepamos que debemos hacer y a que nos debemos atener sino nos mantenemos dentro de patrones establecidos" (p. 2). Y agregan que, por ejemplo, a las niñas se les dan muñecas, implementos de cocina y limpieza (trabajo doméstico), mientras que a los niños se les brinda la oportunidad de interactuar con otros juguetes que potencian sus habilidades físicas y mentales. Este tipo de socialización contribuye a perpetuar la desigualdad de oportunidades para las mujeres, como lo señalan las autoras citadas: "El mundo es la casa del hombre, la casa es el mundo de la mujer" (p. 3). 
Ante este panorama, la alternativa que responsablemente debemos asumir es la del cambio y la transformación de las prácticas educativas, iniciando por la formación de las futuras educadoras y los futuros educadores.

\section{Implementación de algunas experiencias educativas para la superación de las prácticas sexistas}

Desde esa conceptualización del currículo como construcción sociocultural, es factible el diseño de estrategias curriculares que lleven a la implementación de acciones concretas en la dinámica del aula, así lo evidencian los ejemplos que a continuación se mencionan en el ámbito latinoamericano.

Ketterer (2008) nos refiere al caso chileno, en el cual, en los años 90 y como parte de la lucha de las mujeres chilenas, se incorpora el género en la política educativa, para fortalecer, con otros temas, la socialización y el respeto por la diversidad.

En Argentina, también hay evidencias de experiencias, así lo señalan Fioretti et al. (2002), quienes presentan el diseño de una estructura curricular “(...) que eduque a los futuros educadores/ as con un perfil no discriminador, particularmente no sexista respecto a los contenidos ideológicos que trasmitirán" (p. 171).

En el caso de República Dominicana, la Secretaría de Estado de Educación [SEE] (20008), ha implementado una Guía Didáctica dentro del Proyecto de Cooperación Técnica "Promoción de la Equidad de Género en la Educación Básica”, las temáticas incluidas en esa guía son las siguientes:

- Autoestima: Importancia de la estima y valoración personal para relaciones sanas.

- Identidad y discriminación: Diferentes, pero iguales. Conceptos, elementos de la identidad, diferencia y desigualdad.

- Roles de género: Qué es el género, roles de género, sistema sexo-género, estereotipos de género.

- Hacia una cultura de paz: Elementos para la resolución de conflictos, negociación, violencia en la escuela y violencia intrafamiliar.

- Los derechos de las mujeres son derechos humanos: 8 de marzo, Día Internacional de la Mujer. 25 de noviembre, Día Internacional de la No Violencia contra la Mujer.

El objetivo es que esta Guía pueda servir de inspiración al profesorado para llevar a cabo una práctica no sexista en el salón de clase.

En España, como lo menciona Blanco (2004), con la reforma educativa de los años 90, los diseños curriculares de los niveles de primaria y secundaria contemplan el tema de la igualdad de oportunidades entre los sexos, con la introducción de dicho contenido transversal que incorpora la cuestión de género de manera explicita en los contenidos de la enseñanza y en los contenidos de las Ciencias Sociales como una nueva dimensión.

En la Carrera de Pedagogía con Énfasis en Educación Preescolar, de la Universidad Nacional, la temática de género, con otras más, se ha incorporado como parte de los temas transversales del plan de estudios, entendiendo temas transversales como: "Temas socialmente emergentes que permiten o enfatizan en la responsabilidad pública de estudiante y la carrera" (División de Educación Básica, 2005, p. 38), se pretende que dichos temas estén presentes a lo largo de la formación en esta carrera o bien como contenidos específicos de los cursos, y de esta manera establecer un vínculo con la realidad. 
Es importante comentar que, en la revisión de la malla curricular de esta carrera, no se visualiza ningún curso específico con la temática de género, tampoco en la lista de cursos optativos.

El curso de Educación para la salud y la calidad de vida incluye el tema de "Sexualidad humana" y dentro de este como subtema: "El género como arco iris y diversidades sexuales" y el de "la construcción de la identidad sexual". Otro de los cursos en que se explicita la temática de género es el de "Diversidad y currículo preescolar", con el nombre "género y educación preescolar".

Es decir, de los 44 cursos que componen dicho plan de estudios, solamente dos de ellos mencionan de manera directa en sus temáticas el género; y no hay ningún curso "exclusivo" que lo aborde. No obstante, en muchos de los cursos se podría y debería ser más explicito el desarrollo de está temática, por ejemplo: Desarrollo humano y educación, Estrategias para el desarrollo personal y social del niño y la niña preescolar, Literatura para niños en la educación preescolar, Materiales y recursos didácticos en la educación preescolar, Relaciones interpersonales en los procesos pedagógicos, La niñez y sus derechos en el contexto costarricense, Tendencias actuales en la educación preescolar, Retos de la educación contemporánea y Dinámica en el aula preescolar.

Esta situación es preocupante, ya que el género como categoría analítica ha propiciado una verdadera discusión y, sobre todo el reconocimiento de la desigualdad histórica de las mujeres en la sociedad y, como lo señala Lamas (1996a), esa diferencia de ser mujer ha cobrado la dimensión de desigualdad. La categoría analítica de género ha abierto el debate para que se cuestionen los postulados que dieron origen a la subordinación de las mujeres y sacar del terreno biológico la diferencia de sexos.

La situación antes descrita permite visualizar que todavía hay muchas tareas pendientes en materia de implementación del tema de género y de estrategias que permitan eliminar las prácticas sexistas del sistema educativo. Como lo señala Tomé (1999): “En efecto la sensibilización hace tomar conciencia al profesorado sobre la necesidad de modificar numerosos aspectos de la vida escolar que se han mostrado contradictorios con el principio de una educación para la igualdad de oportunidades" (p. 187).

\section{Conclusiones}

\section{Aprendizajes construidos...}

De acuerdo con la literatura consultada, hay coincidencia en que la educación es una de las alternativas más pertinentes para lograr la aspiración de la equidad y la justicia en muchos aspectos de las relaciones humanas y, en este caso particular, lo referente a las relaciones asimétricas entre los hombres y mujeres, para superar esa "trampa ideológica", en la que se nos quiere hacer creer que esas relaciones de desigualdad en prejuicio de las mujeres, son naturales e imposibles de cambiar.

Otro punto de encuentro es la necesidad de hacer cambios en la formación docente, los cuales deben ir en la línea de una cultura docente que impulse la autonomía, la independencia, la emancipación y la seguridad, de la educadora y el educador, para hacer frente a la complejidad y retos de la tarea educativa, en especial en el tema de la equidad de género, para transformar las condiciones de una cultura heredada.

Como bien lo señala Araya (2003), la equidad entre los sexos debe ser una meta educativa, para la cual es indispensable el diseño y desarrollo de diferentes estrategias. Y dentro de este marco, agrega que los procesos de formación del profesorado deben reconocer el valor de las desigualdades sociales que emergen de la construcción cultural de género, no con un currículo homogéneo, sino uno que reconozca las diferencias individuales. 
Por tanto, la lucha por la democracia genérica demanda de un verdadero compromiso, pues aunque ha habido avances, todavía: “(...) un mismo título no alcanza el mismo reconocimiento ni produce los mismos efectos bajo el brazo de una mujer que bajo el de un hombre, con lo cual las mujeres se ven abocadas a una estrategia credencialista para contrarrestar sus desventajas de género" (Fernández, 2001, p. 80).

La invitación es a deconstruir el "habitus" de desigualdad y discriminación hacia las mujeres, a desaprender esquemas de relaciones impuestos históricamente y repensar nuevas formas de relación basadas en el respeto a la diversidad y a las individualidades.

\section{Referencias bibliográficas}

Acker, S. (1995). Género y educación. Reflexiones sociológicas sobre mujeres, enseñanza y feminismo. España: Narcea S. A. de Ediciones

Aguado, T. (2003). Pedagogía intercultural. Madrid: Mc.Graw-Hill.

Araya, S. (2001). La equidad de género desde la representación social de las formadoras y formadores del profesorado de la segunda enseñanza. (Tesis doctoral), Universidad de Costa Rica, San José, Costa Rica.

Araya. S. (2003). Un matrimonio conveniente: el género y educación. Educación, 27(2), 11-25.

Araya, S. (2004). Hacia una educación no sexista. Revista Actualidades Investigativas en Educación, 4(2), 1-13. Recuperado de http://revista.inie.ucr.ac.cr/articulos/2-2004/archivos/sexista.pdf

Belmonte, J. y Guillamón. S. (2008). Co-educar la mirada contra los estereotipos de género en TV. Comunicar. Revista Científica de Educomunicación, 16(31), 115-120. doi: 10.3916/c31-200801-014

Berger, P. y Luckman. T. (1984). La construcción social de la realidad. Argentina: Amorroru editores.

Blanco. P. (2004). La perspectiva de género, una necesidad en la construcción de la ciudadanía. Algunas actividades en la formación del profesorado. En M. I. Vera y D. Pérez (Coords.). Simposisio internacional de didáctica de las Ciencias Sociales: Formación de la ciudadanía: las TICs y los nuevos problemas. Simposio llevado a cabo en Asociación Universitaria de Profesores de Didáctica de Ciencias sociales, España. Recuperado de http://dialnet.unirioja. es/servlet/articulo?codigo $=1454213$

Bourdieu, P. (2000). La dominación masculina. Barcelona: Anagrama.

Chaves, A. L. (2002, julio-diciembre) Develando la acción pedagógica en el salón de clases del aula inicial. Revista Electrónica "Actualidades investigativas en educación”, 2(2), 1-21. Recuperado de http://redalyc.uaemex.mx/pdf/447/44720205.pdf 
Chaves, A. L. (2006). La construcción de subjetividades en el contexto escolar. Revista Educación 30(1), 187-200.

De Beauvoir, S. (2000). El segundo sexo. Argentina: Editorial Sudamericana. Recuperado de http:// es.scribd.com/doc/11060308/El-Segundo-Sexo-Authors-Simone-de-Beauvoir-Completo

División de Educación Básica. (2005). Plan de estudios de la carrera de Pedagogía con énfasis en Educación Preescolar. Heredia, Costa Rica: Universidad Nacional.

Fernández. M. (2001). Educar en tiempos inciertos. España: Ediciones Morata, S. L.

Ferro, C. y Carvajal, Z. (en prensa). Un compromiso de género. Revista Casa de la Mujer.

Fioretti, S., Tejero, G y Díaz, P. (2002) . El género: ¿un enfoque ausente en la formación docente? Revista La Aljaba. Segunda época, Vol. 7, 171-186. Recuperado de http://www.biblioteca. unlpam.edu.ar/pubpdf/aljaba/n07a08fioretti.pdf

Gimeno. J. (2002). El curriculum: una reflexión sobre la práctica. Madrid: Ediciones Morata.

Graña, F. (2008). El asalto de las mujeres a las carreras universitarias "masculinas": cambio y continuidad en la discriminación de género. PRAXIS Educativa, 12, 77-86. Recuperado de http://redalyc.uaemex.mx/pdf/1531/153112902008.pdf

Grundy, S. (1998). Producto o praxis del currículum. Madrid: Ediciones Morata.

Ketterer, L. (2008). La transversalización de género en la educación: ¿Qué pasa en las escuelas de Galvarino, la capital indígena de la región de La Araucanía? Revista La Aljaba, Segunda época, 12, 21-32. Recuperado de http://www.biblioteca.unlpam.edu.ar/pubpdf/aljaba/ n12a02ketterer.pdf

Lagarde. M. (1997). Identidad de género y feminismo. Instituto de Estudios de la Mujer (IEM): Universidad Nacional.

Lagarde. M. (s. f.). Género y poderes. Instituto de Estudios de la Mujer (IEM): Universidad Nacional.

Lamas, M. (1996a). La antropología feminista y la categoría de "género". En M. Lamas (Comp.), El género: la construcción cultural de la diferencia sexual (pp. 97-126). México: Porrúa, PUEG/ UNAM.

Lamas, M. (1996b). Uso, dificultades y posibilidades de la categoría de "género". En M. Lamas (Comp.), El género: la construcción cultural de la diferencia sexual (pp. 327-364). México: Porrúa, PUEG/UNAM. 
Scott, J. (1996). El género: una categoría útil para el análisis histórico. En M. Lamas (Comp.), El género: la construcción cultural de la diferencia sexual (pp. 265-302). México: Porrúa, PUEG/UNAM.

Secretaría de Estado de Educación [SEE]. (2008). Proyecto: Promoción de la equidad de género en la educación básica. Guía de recursos para la igualdad de género. Santo Domingo, República Dominicana: Programa Multifase para la Equidad de la Educación Básica.

Subirats, M. (1994, setiembre-diciembre). Conquistar la igualdad: la coeducación hoy. Revista Iberoamericana de Educación, 6, 49-78 Género y Educación. Recuperado de http://www. rieoei.org/oeivirt/rie06a02.pdf

Subirats, M. (1999). Género y escuela. En C. Lomas (Comp.) ¿Iguales o diferentes? Género, diferencia sexual, lenguaje y educación (pp. 19-32). España: Paidós Educador. Recuperado de http://books.google.com.pe/books?id=gaWB9vCkkyEC\&printsec=frontcover\&hl=en\&sou

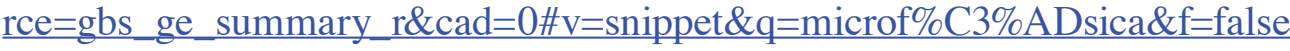

Stainback, S. y Stainback W. (1999). Aulas inclusivas. Madrid: Narcea Edicciones.

Tomé, A. (1999). Un camino hacia la coeducación (instrumentos de reflexión e intervención). En C. Lomas (Comp.), ¿Iguales o diferentes? Género, diferencia sexual, lenguaje y educación (pp. 171-197). España: Paidós. 